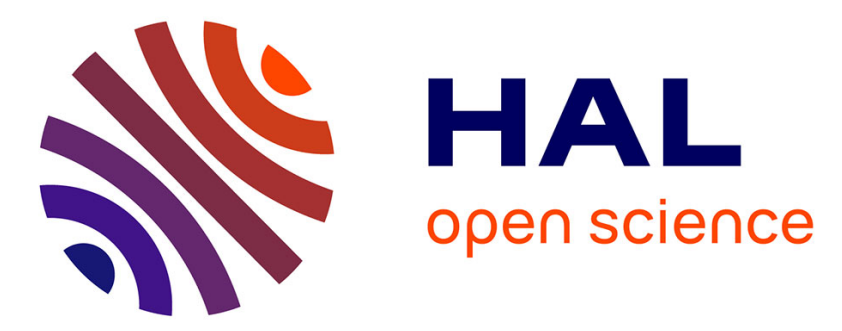

\title{
Density dependence in an age-structured population of great tits: identifying the critical age classes
}

Marlène Gamelon, Vidar Grøtan, Steinar Engen, Eirin Bjørkvoll, Marcel E

Visser, Bernt-Erik Saether

\section{- To cite this version:}

Marlène Gamelon, Vidar Grøtan, Steinar Engen, Eirin Bjørkvoll, Marcel E Visser, et al.. Density dependence in an age-structured population of great tits: identifying the critical age classes. Ecology, 2016, 97 (9), pp.2479-2490. 10.1002/ecy.1442 . hal-03282094

\section{HAL Id: hal-03282094 \\ https://hal.science/hal-03282094}

Submitted on 8 Jul 2021

HAL is a multi-disciplinary open access archive for the deposit and dissemination of scientific research documents, whether they are published or not. The documents may come from teaching and research institutions in France or abroad, or from public or private research centers.
L'archive ouverte pluridisciplinaire HAL, est destinée au dépôt et à la diffusion de documents scientifiques de niveau recherche, publiés ou non, émanant des établissements d'enseignement et de recherche français ou étrangers, des laboratoires publics ou privés. 


\title{
Density dependence in an age-structured population of great tits: identifying the critical age classes
}

\author{
Marlène Gamelon, ${ }^{1,4}$ Vidar Grøtan,,${ }^{1}$ Steinar Engen, ${ }^{2}$ Eirin Bjørkvoll, ${ }^{1}$ Marcel E. Visser,${ }^{3}$ and \\ BERNT-ERIK $\mathrm{S}_{\text {ETHER }}{ }^{1}$ \\ ${ }^{1}$ Centre for Biodiversity Dynamics, Department of Biology, Norwegian University of Science and Technology, Trondheim 7491 \\ Norway \\ ${ }^{2}$ Centre for Biodiversity Dynamics, Department of Mathematical Sciences, Norwegian University of Science and Technology, \\ Trondheim 7491 Norway \\ ${ }^{3}$ Department of Animal Ecology, Netherlands Institute of Ecology (NIOO-KNAW), Wageningen, 6700 AB The Netherlands
}

\begin{abstract}
Classical approaches for the analyses of density dependence assume that all the individuals in a population equally respond and equally contribute to density dependence. However, in age-structured populations, individuals of different ages may differ in their responses to changes in population size and how they contribute to density dependence affecting the growth rate of the whole population. Here we apply the concept of critical age classes, i.e., a specific scalar function that describes how one or a combination of several age classes affect the demographic rates negatively, in order to examine how total density dependence acting on the population growth rate depends on the age-specific population sizes. In a 38-yr dataset of an age-structured great tit (Parus major) population, we find that the age classes, including the youngest breeding females, were the critical age classes for density regulation. These age classes correspond to new breeders that attempt to take a territory and that have the strongest competitive effect on other breeding females. They strongly affected population growth rate and reduced recruitment and survival rates of all breeding females. We also show that depending on their age class, females may differently respond to varying density. In particular, the negative effect of the number of breeding females was stronger on recruitment rate of the youngest breeding females. These findings question the classical assumptions that all the individuals of a population can be treated as having an equal contribution to density regulation and that the effect of the number of individuals is age independent. Our results improve our understanding of density regulation in natural populations.
\end{abstract}

Key words: age-structured population; Bayesian; density dependence; density regulation; integrated population model; Parus major; recruitment; survival.

\section{INTRODUCTION}

Fluctuations in population size are dependent on the combined effects of density-independent (stochastic) and density-dependent (deterministic) factors (Lande et al. 2003). Density dependence operates through a negative feedback between the population growth rate and the population size at one or more time steps (Royama 1992, Turchin 1995, Berryman et al. 2002, Lande et al. 2002, Brook and Bradshaw 2006). In many cases, density dependence results in regulation of the population fluctuations around a mean population size, the carrying capacity (Sinclair 1989). Consequently, that affects many important characteristics of the population dynamics that have implications for the management of populations. For example, the form of the density regulation affects the sustainable rate of harvest of exploited populations (Sæther et al. 1996, Hilborn and Walters 2003) and persistence time of populations vulnerable to extinction (Lande et al. 2003).

Manuscript received 25 June 2015; revised 1 March 2016; accepted 5 April 2016. Corresponding Editor: E. E. Holmes.

${ }^{4}$ E-mail: marlene.gamelon@ntnu.no
Estimates of the strength of density dependence in population dynamics have traditionally been based on time-series analyses of population counts (Royama 1992, Turchin 1995, Lande et al. 2003, Coulson et al. 2008). Thus, the potential negative effect of density on population growth rate is estimated by a phenomenological relationship between population growth rate and total population size. Such a phenomenological relationship at the level of the population is based on the assumption that all individuals irrespective of their age are exchangeable in terms of (1) responses to varying density and (2) in their competitive effect on other individuals (Krebs 2002). If the age structure fluctuates temporally and the previously mentioned assumptions do not hold, such time-series analyses of population counts will lead to biased estimates of the density-dependent component of the population dynamics.

The assumptions of equal responses and equal contribution of all ages to density dependence are often violated in age-structured populations. Indeed, there is now compelling evidence that individuals of different ages can differ in their response to density-dependent factors. For instance, in their review on large mammals and 
herbivores, Bonenfant et al. (2009) highlighted that density-dependent responses of survival and fecundity rates are common and strongly age-dependent. Similarly, an increase in population density strongly affects specifically adult survival in the red-backed shrikes (Lanius collurio) and has virtually very little effect on juvenile survival (Abadi et al. 2012). But interestingly, in age-structured populations subject to density dependence, the influence of an individual on other ones may also depend on its age and consequently individuals may differently contribute to density dependence. For instance, in long-lived territorial birds in which adults breed in the same territory for several years and new breeders are dependent on occupying vacant territories, the number of adults, specifically, negatively impacts the number of new recruits in the population (Sæther et al.2002). Surprisingly, to our knowledge, such an age-specific contribution to density dependence has been poorly explored in terrestrial systems.

Nearly forty years ago, an important contribution to the analysis of density-dependence in age-structured populations was provided by Charlesworth (1972), who introduced the concept of the critical age class. This denotes the age class or combination of age classes in which the variation in the number of individuals most strongly affects the density regulation. However, this concept has had little influence on empirical analyses of population dynamics (e.g., Beddington 1974). Hence, whether all age classes or only the size of some specific age classes contributes to density-dependent effects in age-structured populations remains an open question. This is most likely due to the difficulty of censusing and determining the age of all the individuals in a population. Thanks to recent methodological advances, accounting for observation errors in population census while investigating density dependence is now possible (Dennis et al. 2006, Lillegård et al. 2008, Abadi et al. 2012, Lebreton and Gimenez 2013, Schaub et al. 2013).

Here, we fill this gap by identifying the critical age classes (sensu Charlesworth 1972, 1973) for density dependence that mostly affect the population growth rate and its components caused by variation in survival and fecundity in an age-structured population. The great tit (Parus major) population in Hoge Veluwe National Park (the Netherlands) has highly fluctuated in size during the last $40 \mathrm{yr}$ (Reed et al. 2013a), and there is evidence based on time-series analyses of strong density dependence in the dynamics of this population (Both 1998b, Grøtan et al. 2009, Reed et al. 2013a, b). First, using a Bayesian integrated population model (IPM; see Schaub and Abadi 2011 for a review), we estimated age-specific demographic rates and age-specific numbers, including observation error in records of individuals as well as uncertainty in the age of some monitored birds. Then, by relaxing the assumption of equal contribution of all birds to the density dependence, we examined how the different age classes contributed to the observed variation in demographic rates and determined which age classes contribute the most to the total density dependence acting on the growth rate of our population.

\section{Materials And Methods}

Study species and study area

The data analyzed come from a long-term study of a great tit population at Hoge Veluwe National Park in the Netherlands $\left(52^{\circ} 02^{\prime} \mathrm{N}, 5^{\circ} 51^{\prime} \mathrm{E}\right)$, a mixed pine-deciduous wood of 171 ha (see Reed et al. $2013 b$ for further details on the study area and procedure for data collection). The great tit is a $18-20 \mathrm{~g}$ small passerine bird species abundant in European gardens and woodlands and not migratory (Perrins and McCleery 1989). It is a short-lived species; the oldest breeding female recorded in our population was $7 \mathrm{yr}$ of age. This hole-nester accepts nest boxes for breeding, allowing monitoring of the whole population as long as more nest boxes than required are provided. Females usually start reproduce in the second calendar year of life (Perrins 1979). They produce one clutch of up to 18 eggs laid each year, although double-clutching may be sometimes observed (Husby et al. 2009). A common measure of breeding success is the number of recruits, corresponding to the number of young which survive long enough to breed in the nest boxes (Perrins and McCleery 1989). In the study area, very few females bred in natural cavities and most of them bred in nest boxes (Grøtan et al. 2009). More nest boxes than required were provided to ensure that the availability of nest boxes did not influence population density (Reed et al. 2013b). We focused on the years between 1973 and 2012 when the study area remained the same size and the number of nest boxes was approximately constant (Reed et al. 2013b). As the study area is surrounded by a matrix of potential suitable habitats for great tits, the population is open to immigration and emigration (Reed et al. 2013b).

\section{Demographic data}

Three types of demographic data were available for this population: capture-recapture (CR) data, total number of breeding females at year $t$, and number of recruits produced by breeding females. During the breeding season (April to June) each year, nest boxes were visited at least once a week. All young were ringed on day seven post-hatching. The ringed mothers were identified and the unringed mothers were given a ring allowing future identifications. These unringed mothers (1,955 females during the study period) were assumed to have immigrated into the population the current year. It was possible to exactly age most of these immigrants (1,686 females), resulting in a total of only 269 breeding females of unknown age over the course of the study period. Overall, CR data were available for 2,691 breeding females of known age (1,005 locally fledged females plus 1,686 females that fledged elsewhere but immigrated to the study area to breed). 
The second type of demographic data available was an estimate of the total number of counted breeding females each year $t\left(C_{t}\right)$ on the study site. Rates of nonbreeding are very low in our study population (Bauchau and Van Noordwijk 1995), thus breeding population size is a good proxy for the total number of females of age $1+$ in the population. We will refer to $C_{t}$ as the population count with the understanding that this is a population count of breeding females only. To calculate the population count for a given year, we summed the number of breeding females of known age, the number of breeding females of unknown age and an estimate of the number of breeding females not caught (and thus not identified nor aged) because they have deserted their clutches early in the breeding attempt (Reed et al. 2013b). The number of females of the latter type could be estimated by the number of clutches found without a mother. We assumed that any clutch found without an identified mother corresponded to a breeding female that was present but not captured. There were 536 clutches without an identified mother in the study period.

The last type of data was age-class specific counts of breeding females and the age-class specific contribution to recruitment. Based on the life history of great tits, we used four age classes of breeding females with age class 1 corresponding to the first year of breeding (second calendar year of life), age class 2 to the second year of breeding and third calendar year of life, age class 3 to the third year of breeding and fourth calendar year of life and age class 4 to older breeding females. Female fledglings were ringed on day seven and were recorded as recruited to the breeding population if they were caught as a breeding female in a subsequent year (Both et al. 1999). This gave us the observed number of local female fledglings in year $t$ that successfully became a first year breeding female in year $t+1$. This we termed the breeding recruitment for year $t\left(J_{t}\right)$. This recruitment could be broken down by the age-class of the mother: first year breeder, second year, etc. This provided estimates of the number of recruits by mothers of age class $i$ in year $t\left(J_{i, t}\right)$. In addition, we recorded the total number of breeding females of each age class $i$ in year $t\left(B_{i}, t\right)$. In total, 824 daughters of known age mothers locally recruited during the study period.

\section{Annual age-specific demographic rates and true age-specific numbers}

We aimed to estimate annual age-specific survival and recruitment rates as well as the true (as opposed to observed) annual age-specific numbers of females. Our observed annual number of breeding females of different age classes contains a number of sources of observation error. There were females for which the age class was unknown (some immigrants). Although the recapture probability was high on the study site (Reed et al. 2013b), not all females were recaptured, resulting in errors and uncertainty in the number of females in the different age classes. This also leads to errors and uncertainty in the estimates of survival and recruitment. In addition, there was a possibility of double counts. For instance if one female produced two clutches but was only identified in one of them because she has deserted one of the clutches. Lastly, there was the possibility that some clutches were missed because females bred in natural cavities.

To account for these issues, we analyzed simultaneously CR data of known age females, data on the reproductive success of breeding females of known age $\left(J_{i, t}\right.$ and $\left.B_{i, t}\right)$, and the population count $C_{t}$ using an IPM. Briefly, an IPM (Schaub and Abadi 2011) is the joint analysis of different datasets like for instance CR data and census data. This joint analysis of these different sources of data increases the precision of the estimates of the shared parameters. Inference is based on the joint likelihood, corresponding to the multiplication of the likelihoods from the single datasets (CR data, data on reproductive success and population count; Kéry and Schaub 2012). The likelihoods of the different datasets were specified as follows in the IPM. For CR data of breeding females of known age, we used the Cormack-Jolly-Seber model (Lebreton et al. 1992) which allows estimation of annual survival between age class $i$ and $i+1\left(S_{i, t}\right)$ and recapture $\left(P_{t}\right)$ probabilities.

For data on reproductive success, we assumed that the observed number of daughters locally recruited per age class $i\left(J_{i, t}\right)$ is Poisson distributed with $J_{i, t} \sim \operatorname{Poisson}\left(B_{i, t}\right.$ $\left.\times F_{i, t}\right)$, where $B_{i, t}$ is the observed number of breeding females of age class $i$ and $F_{i, t}$ is the recruitment rate of females of age class $i$ at year $t . F_{i, t}$ is the term we are estimating and is the contribution of mothers of age class $i$ to recruitment into the age class 1 breeding class next year. Considering the contribution of mothers of age class $i$ to recruitment to the age class 1 breeding females next year instead of the clutch size or the number of fledglings produced allowed emigration and mortality in the first year of life to be included in the recruitment estimate.

For the population count data, we used a state-space model (de Valpine and Hastings 2002) which consisted of a process model describing how the population size and structure changed over time as well as an observation model (Besbeas et al. 2002). In details, for the process model, we considered a pre-breeding age-structured model with the four predefined age classes and assumed that reproduction starts in the second calendar year of life when females enter their first year breeding and our age class 1 (Perrins 1979). The total number of breeding females of age class $i$ in year $t$ was denoted $N_{i, t}$. $N_{i, t}$ was defined as $N_{i, t}=n_{i, t}+I_{i, t}+A_{i, t}$, where $n_{i, t}$ is the number of local females in each age class $i$ in year $t, I_{i, t}$ is the number of immigrants of age class $i$ but for which it was impossible to give an exact age and $A_{i, t}$ is the number of known age immigrants of age class $i$. To account for demographic stochasticity, especially important in small populations (Lande et al. 2003), we used Poisson and binomial processes to describe the number of local breeding females in each age class $\left(n_{i, t}\right): n_{1, t+1}$ 
$\sim \operatorname{Poisson}\left(N_{1, t} \times F_{1, t}+N_{2, t} \times F_{2, t}+N_{3, t} \times F_{3, t}+N_{4, t}\right.$ $\left.\times F_{4, t}\right), n_{2, t+1} \sim \operatorname{Bin}\left(N_{1, t}, S_{1, t}\right), n_{3, t+1} \sim \operatorname{Bin}\left(N_{2, t}, S_{2, t}\right)$ and $n_{4, t+1} \sim \operatorname{Bin}\left(N_{3, t}, S_{3, t}\right)+\operatorname{Bin}\left(N_{4, t}, S_{4, t}\right)$. For the immigrant females $I_{i, t}$ for which it was impossible to give an exact age, we considered that each year $t$, a proportion of them are females of age class $i$. This allowed taking into account uncertainty on the age of these immigrant females without making any explicit assumption about their exact age. Since virtually all individuals breed in the nest boxes, we assumed that all new immigrants were observed. Note that females were classified as immigrants only in their year of arrival into the study population and then join the local population. The true number of breeding females in the population at year $t\left(N_{t o t, t}\right)$ is then $\sum_{i=1}^{4} N_{i, t}$. The observation model describes the link between the population counts $C_{t}$ and the true number of breeding females in the population $\left(N_{t o t, t}\right)$. We assumed that: $C_{t} \sim N\left(N_{t o t, t}, \sigma_{C}^{2}\right)$ truncated to positive values with $\sigma_{C}^{2}$ which incorporates observation errors of the counts. The observation model accounts for both count errors (females unobserved or double-counted) and lack of fit of the state equations to the true dynamics of the population (Schaub and Abadi 2011).

Assuming independence among the datasets, the likelihood of the IPM is given by the product of the likelihoods of the three different datasets, namely population counts $C_{t}$, reproductive $\left(J_{i, t}\right.$ and $\left.B_{i, t}\right)$ data and CR data (Kéry and Schaub 2012). It is noteworthy that most of the breeding females may be found in the three different datasets, in particular the breeding females of known age. Thus, the assumption of independence is violated in our study. However, a recent simulation study of IPM performance has shown that the violation of the assumption of independence does not have a strong impact on the performance of the estimators and highlighted a gain in precision and accuracy when all three datasets (population counts, reproductive success and CR data) are analyzed simultaneously into an IPM (Abadi et al. 2010). There is no goodness-of-fit test available for the IPM (Schaub and Abadi 2011). However, we could test the CR model outside of the IPM using U-CARE (Choquet et al. 2009). We found no lack of fit (global test: $\chi^{2}(77)=51.981$, $P=0.987)$.

We were interested in estimating annual age-specific survival and recruitment rates while allowing correlated variability among these demographic rates. We used a hierarchical formulation of the IPM to get the best possible annual estimates of the demographic rates, not inflated by sampling variation (Kéry and Schaub 2012). In this formulation, the annual estimates are thought to originate from a random process with a common mean and a constant temporal variance (see e.g., Schaub et al. 2012, 2013 for a similar approach). Recruitment was specified on the $\log$-scale $\log \left(F_{i, t}\right)=\mu_{F i}+\varepsilon_{F i, t}$, where $\mu_{F i}$ is the mean contribution of mothers of age class $i$ to recruitment next year and $\varepsilon_{F i, t}$ is the age-specific temporal residual. The logit link was used for survival so that $\operatorname{logit}\left(S_{i, t}\right)=\mu_{S i}+\varepsilon_{S i, t^{\circ}} \varepsilon$ is the matrix including the temporal residuals of the eight demographic rates (i.e., one temporal residual for recruitment rate $\varepsilon_{F i, t}$ and one temporal residual for survival rate $\varepsilon_{S i, t}$ per age class $i$ ). These residuals were treated as a realization from a multivariate normal distribution $\varepsilon \sim M V N(0, \Sigma)$ with $\Sigma$ the variance-covariance matrix allowing correlated variability. The recapture probability, assumed to be ageindependent, was modeled with random time variation as well $\operatorname{logit}\left(P_{t}\right)=\mu_{P}+\varepsilon_{P t}$.

The IPM was fit within the Bayesian framework, and noninformative priors (Appendix S1) were specified for all the parameters allowing the inference to be dominated by information in the data and not by the information in the priors. Markov chain Monte Carlo (MCMC) simulation was used for parameter estimation. To assess convergence, we ran four independent chains with different starting values for 100,000 MCMC iterations, with a burn-in of 50,000 iterations thinning every 100 th observation resulting in 2,000 posterior samples. We used the Brooks and Gelman diagnostic $\hat{R}$ to assess the convergence of the simulations and used the rule $\hat{R}<1.02$ to determine whether convergence has been reached (Brooks and Gelman 1998). The analyses were implemented using JAGS version 3.4.0 (Plummer 2003) called from R version 3.1.1 (R Development Core Team 2011) with package R2jags (Su and Yajima 2012). The JAGS code for fitting the IPM is available in Appendix S3. To ensure that the priors for initial population sizes do not influence estimates of demographic rates and age-specific numbers the first year of the study (i.e., in 1973), only the years between 1974 and 2012 were used in the analyses.

\section{The effects of age-class numbers on age-specific demographic rates}

The IPM was used to estimate age-specific demographic and age-specific true numbers. Once these were estimated, linear regressions were used to examine how the different age classes contributed to the observed variation in age-specific demographic rates. The following regression models were used:

$$
\begin{aligned}
\log \left(F_{i, t}\right)= & \gamma_{F_{i}}+\beta_{F_{i}, N_{1}} N_{1, t}+\beta_{F_{i}, N_{2}} N_{2, t}+\beta_{F_{i}, N_{3}} N_{3, t} \\
& +\beta_{F_{i}, N_{4}} N_{4, t}+\operatorname{res}_{F_{i, t}}
\end{aligned}
$$

and

$$
\begin{aligned}
\operatorname{logit}\left(S_{i, t}\right)= & \gamma_{S_{i}}+\beta_{S_{i}, N_{1}} N_{1, t}+\beta_{S_{i}, N_{2}} N_{2, t}+\beta_{S_{i}, N_{3}} N_{3, t} \\
& +\beta_{S_{i}, N_{4}} N_{4, t}+\operatorname{reS}_{S_{i, t}}
\end{aligned}
$$

where $\gamma$ are the intercepts, $\beta$ are the regression coefficients and res are the residuals of the regressions corresponding to the variation in demographic rates not explained by age-specific numbers. These regressions were fit for each posterior sample (2,000 in total). As $F_{i, t}, S_{i, t}$ and $N_{j, t}$ in Eqs. 1 and 2 are estimated in the IPM model, they are not 
contaminated with sampling variance and observation errors and thus this approach does not lead to spurious detection of density dependence (Freckleton et al. 2006, see Schaub et al. 2013 for a similar approach). Because we were interested in the effect of each age class on survival and recruitment rates, the regression coefficients $\beta_{F_{i}, N_{j}}$ and $\beta_{S_{i}, N_{j}}$ were calculated for each posterior sample. Then, from these 2,000 estimates of $\beta_{F_{i}, N_{j}}$ and $\beta_{S_{i}, N_{j}}$, the $95 \%$ credible intervals (CRI) and the probability for the coefficients to be lower than zero (i.e., $P(\beta<0)$ ) were computed. For instance, a high probability $P\left(\beta_{F_{1}, N_{2}}<0\right)$ would indicate a high probability for a negative effect of the number of females in age class 2 on recruitment rates of age class 1 . Note that we looked for possible multicollinearity among explanatory variables which can lead to high standard errors and difficulties in interpreting parameter estimates in regressions (Graham 2003) by computing the posterior modes of pairwise correlation coefficients between $N_{i, t}$ and $N_{j, t}$. They varied from 0.010 , 95\% CRI $(-0.174,0.193)$ to $0.294,95 \%$ CRI (0.027, $0.524)$. Since collinearity was low, all age-specific numbers $N_{i, t}$ were included in the regression model as explanatory variables (Eqs. 1 and 2; Price et al. 2009, 2010).

\section{The effects of age-class numbers on population growth rate}

As derived parameter from the IPM, we computed the population growth rate $\lambda$ in year $t$ as $\lambda_{t}=\frac{N_{t o t, t+1}}{N_{t o t, t}}$ for each posterior sample. To determine how the number of females in the different age classes contributed to the observed variation in population growth rate, we explored the phenomenological relationship between population growth rate ( $\lambda_{t}$ on a log-scale) and age-specific true numbers $N_{j, t}$. Hence:

$$
\begin{aligned}
\log \left(\lambda_{t}\right)= & \gamma_{\lambda}+\beta_{\lambda, N_{1}} N_{1, t}+\beta_{\lambda, N_{2}} N_{2, t}+\beta_{\lambda, N_{3}} N_{3, t} \\
& +\beta_{\lambda, N_{4}} N_{4, t}+\operatorname{res}_{\lambda_{t}}
\end{aligned}
$$

where $\gamma_{\lambda}$ is the intercept, $\beta_{\lambda, N_{j}}$ are the regression coefficients and res $\lambda_{t}$ are the residuals of the regression corresponding to the variation in population growth rate not explained by age-specific numbers.

We also investigated the phenomenological relationship between population growth rate and true total number of breeding females. We used a Ricker densitydependence model, which is a simple way of representing density-dependent feedback in the per-unit-abundance growth rate (Ricker 1954, Dennis and Taper 1994):

$$
\log \left(\lambda_{t}\right)=\gamma_{\lambda}{ }^{\prime}+\beta_{\lambda, N_{t o t}} N_{t o t, t}+\operatorname{res}_{\lambda_{t}}{ }^{\prime}
$$

where $\gamma_{\lambda}{ }^{\prime}$ is the intercept, $\beta_{\lambda, N_{\text {tot }}}$ is the regression coefficient and $r e s_{\lambda_{t}}{ }^{\prime}$ are the residuals of the regression corresponding to the variation in population growth rate not explained by the total number of breeding females. As previously done for recruitment rates (Eq. 1) and survival rates (Eq. 2), these regressions (Eqs. 3 and 4) were fit for each posterior sample (2,000 in total). The regression coefficients $\beta_{\lambda, N_{i}}$ and $\beta_{\lambda, N_{\text {tot }}}$ were calculated for each posterior sample. Then, CRI and the probability for the coefficients to be lower than zero (i.e., $P(\beta<0)$ ) were computed.

All these analyses were performed with $\mathrm{R}$ software ( $\mathrm{R}$ Development Core Team 2011) using the $\operatorname{lm}()$ function for the linear regressions.

\section{RESUlTS \\ Age-specific numbers}

Our parameter estimates are presented as the mean of the posterior distribution with their associated 95\% CRI. The estimated total number of breeding females fluctuated between $60.67,95 \%$ CRI $(49.00,73.00)$ and 201.61, 95\% CRI $(185.00,218.00)$ over the study period. The mean population growth rate (calculated as $\left.\exp \left(\frac{\sum_{t} \log \left(\lambda_{t}\right)}{38}\right)\right)$ was estimated to be $1.003,95 \%$ CRI $(0.999,1.006)$. The mean of the posterior was close to 1 and the CRI included 1 reflecting that the population fluctuated around a mean population size over the course of the study period. The age-specific numbers showed large temporal fluctuations (Fig. 1A). Correspondingly, the coefficients of variation of the number of breeding females over the study period were estimated to $0.363,95 \%$ CRI $(0.334,0.391)$ for age class 1 , to $0.375,95 \%$ CRI $(0.318,0.435)$ for age class 2 , to $0.464,95 \%$ CRI $(0.384,0.547)$ for age class 3 and to $0.499,95 \%$ CRI $(0.383,0.626)$ for age class 4 . On average, the breeding population was composed of $52.1 \%, 95 \%$ CRI $(50.8 \%, 53.6 \%)$ of females from age class $1,25.1 \%$, $95 \%$ CRI $(24.0 \%, 26.3 \%)$ of age class $2,13.5 \%, 95 \%$ CRI $(12.5 \%, 14.4 \%)$ of age class 3 and $9.3 \%, 95 \%$ CRI $(8.0 \%$, $10.7 \%$ ) of older females.

\section{Age-specific demographic rates}

The mean recapture probability was estimated to be $93.9 \%, 95 \%$ CRI $(91.8 \%, 95.5 \%)$ indicating a high recapture rate. The estimated demographic rates in all age classes exhibited large temporal variation (Appendix S2). Age class 2 had the highest estimated mean survival and the probability that age class 2 survival was greater than the survival for all other age classes $\left(P\left(\hat{S}_{2}>\hat{S}_{i}\right)\right.$ for $i=1,3$ or 4 ) was $97.8 \%$. Age class 4 had the lowest estimated mean survival and the probability that age class 4 survival was lower than all other age classes' survival $\left(P\left(\hat{S}_{4}<\hat{S}_{i}\right)\right.$ for $i=1,2$ or 3$)$ was $100 \%$. Age class 3 had a lower estimated mean survival than age class 1 and the probability that age class 3 survival was lower than age class 1 survival $\left(P\left(\hat{S}_{3}<\hat{S}_{1}\right)\right)$ was $91.2 \%$. Age class 2 had again the highest estimated mean recruitment rate and the probability that age class 2 recruitment was greater than all other age classes' recruitment $\left(P\left(\hat{F}_{2}>\hat{F}_{i}\right)\right.$ for $i=1,3$ or 4 ) was $70.6 \%$. Age class 1 had the lowest 

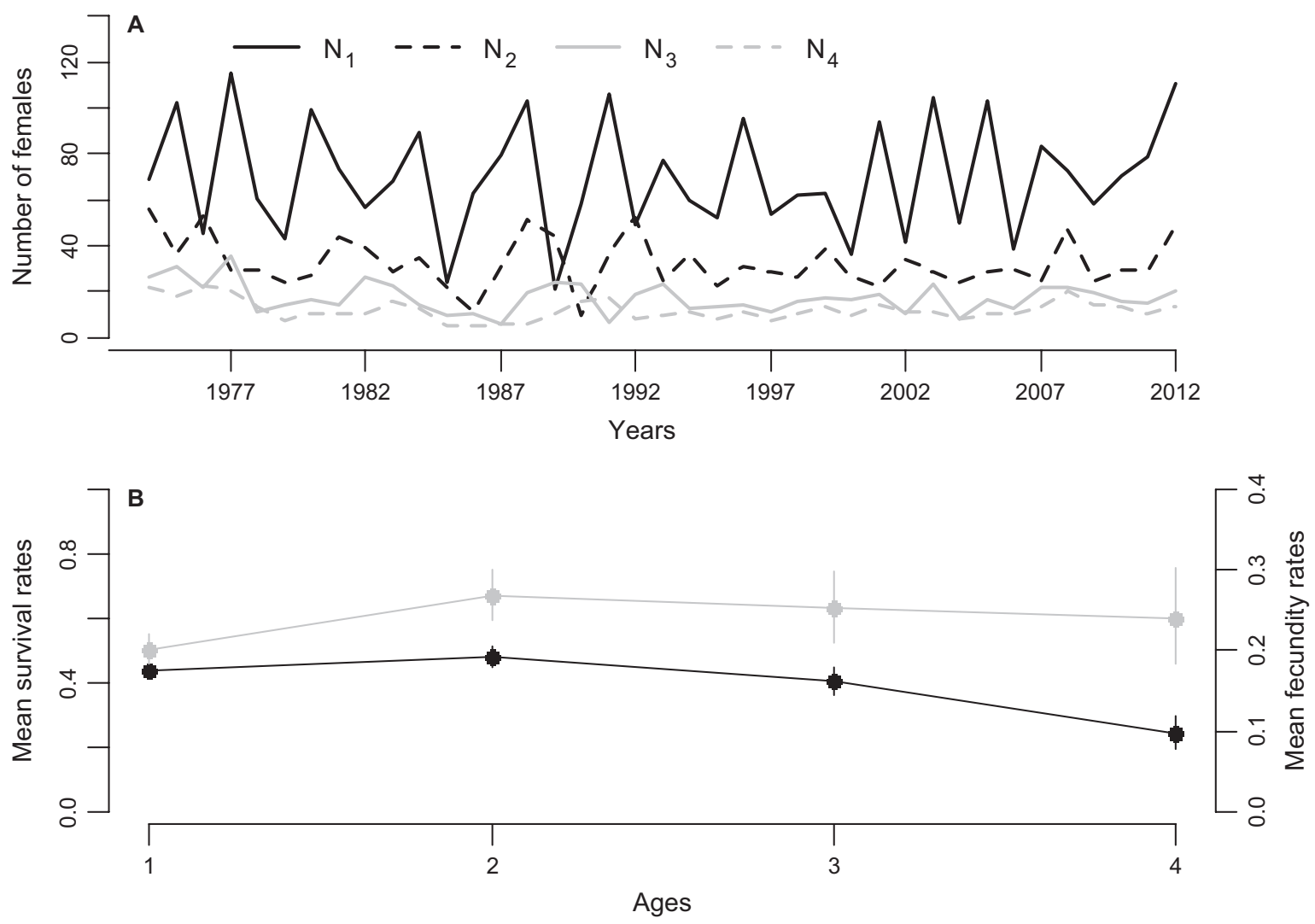

FIG. 1. (A) Posterior means of the age-specific numbers of breeding females $N_{i}$ estimated from the IPM between 1974 and 2012 in the great tit population of Hoge Veluwe National Park, the Netherlands. (B) Posterior means of the age-specific mean survival (in black) and recruitment (in grey) rates between 1974 and 2012 and their associated 95\% CRI.

estimated mean recruitment rate and the probability that age class 1 recruitment was lower than recruitment for all other age classes $\left(P\left(\hat{F}_{1}<\hat{F}_{i}\right)\right.$ for $i=2,3$ or 4$)$ was $88.7 \%$. Age class 3 had a higher estimated mean recruitment than age class 4 and the probability that age class 3 recruitment was higher than age class 4 recruitment $\left(P\left(\hat{F}_{3}>\hat{F}_{4}\right)\right)$ was $62.6 \%$. Therefore, estimated mean survival and recruitment rates decreased from age class 2 onwards indicating senescence in both survival and recruitment rates in this great tit population (Fig. 1B).

\section{The effects of age-class numbers on age-specific demographic rates}

The $\beta_{N_{i}}$ values indicated how the number of females in age class $N_{i}$ contributed to the observed variation in agespecific demographic rates. Thus, negative $\beta_{N_{i}}$ values indicate that higher number of females in the age class $N_{i}$ translates to lower survival and/or recruitment. The mean of the posterior $\beta_{N_{1}}$ was always negative and the CRI did not include zero (Table 1, first column) reflecting that the number of females in age class 1 affected survival and recruitment rates of all age classes. Thus, the higher the number of females in age class 1, the lower the recruitment rates (Fig. 2A) and the lower the survival rates (Fig. 3A) for all age classes. The probability that this negative effect of age class 1 on survival and recruitment rates was stronger than the effects of age class 2 , age class 3 or age class $4\left(P\left(\beta_{N_{1}}<\beta_{N_{i}}\right)\right.$ for $i=2,3$ or 4$)$ was $>58.1 \%$ indicating that the per capita effect on density dependence is the largest for age class 1 . Moreover, age class 1 being the biggest age class, age class 1 was the age class contributing the most to the observed variation in survival and recruitment rates.

The mean of the posterior $\beta_{N_{2}}$ was always negative for recruitment rates and the CRI did not include zero (Table 1, second column) reflecting that the number of females in age class 2 affected recruitment rates of all age classes. Thus, the higher the number of females in age class 2, the lower the recruitment rates (Fig. 2B) for all age classes. The probability that this negative effect of age class 2 on recruitment rates was stronger than the effects of age class 3 or age class $4\left(P\left(\beta_{F, N_{2}}<\beta_{F, N_{i}}\right)\right.$ for $i=3$ or 4 ) was $>66.8 \%$ indicating that, after age class 1 , the per capita effect on density dependence is the largest for age class 2. Moreover, age class 2 being the second largest age class, age class 2 was the second age class contributing the most to the observed variation in recruitment rates. The mean of the posterior $\beta_{N_{2}}$ was also always negative for survival rates however the CRI included zero in 
TABLE 1. Effects of the number of breeding females $N_{j}$ in age class $j$ on recruitment rates $F_{i}$ (log-transformed; contribution of mothers of age class $i$ to age class 1 breeding females) and on survival rates $S_{i}$ (logit-transformed) of age class $i$. Displayed are the means of the posterior distributions of the regression coefficients $\beta$ and their associated $95 \% \mathrm{CRI}$. In parentheses are the posterior probability that the coefficients are less than zero $P(\beta<0)$ (among the 2000 posterior samples).

\begin{tabular}{|c|c|c|c|c|}
\hline \multirow{3}{*}{$\begin{array}{l}\text { Demographic } \\
\text { rates of age } \\
\text { class } i \\
\text { (responses) }\end{array}$} & \multicolumn{4}{|c|}{ Number of breeding females of age class $j$ (covariates) } \\
\hline & $N_{1}$ & $N_{2}$ & $N_{3}$ & $N_{4}$ \\
\hline & $\beta_{N_{1}}$ & $\beta_{N_{2}}$ & $\beta_{N_{3}}$ & $\beta_{N_{4}}$ \\
\hline $\log \left(F_{1}\right)$ & $\begin{array}{c}-0.023(-0.029,-0.018) \\
(1.000)\end{array}$ & $\begin{array}{l}-0.018(-0.032 \\
-0.005)(0.995)\end{array}$ & $\begin{array}{c}-0.003(-0.028,0.021) \\
(0.609)\end{array}$ & $\begin{array}{c}0.012(-0.029,0.050) \\
(0.259)\end{array}$ \\
\hline $\log \left(F_{2}\right)$ & $\begin{array}{c}-0.017(-0.023,-0.012) \\
(1.000)\end{array}$ & $\begin{array}{l}-0.016(-0.029 \\
-0.004)(0.995)\end{array}$ & $\begin{array}{c}-0.005(-0.028,0.016) \\
(0.693)\end{array}$ & $\begin{array}{c}0.009(-0.024,0.043) \\
(0.271)\end{array}$ \\
\hline $\log \left(F_{3}\right)$ & $\begin{array}{c}-0.019(-0.027,-0.013) \\
(1.000)\end{array}$ & $\begin{array}{l}-0.016(-0.031 \\
-0.003)(0.992)\end{array}$ & $\begin{array}{c}-0.001(-0.026,0.023) \\
(0.530)\end{array}$ & $\begin{array}{c}0.009(-0.029,0.046) \\
(0.296)\end{array}$ \\
\hline $\log \left(F_{4}\right)$ & $\begin{array}{c}-0.020(-0.029,-0.012) \\
(1.000)\end{array}$ & $\begin{array}{l}-0.016(-0.033 \\
-0.001)(0.981)\end{array}$ & $\begin{array}{c}-0.010(-0.040,0.018) \\
(0.746)\end{array}$ & $\begin{array}{c}0.010(-0.034,0.055) \\
(0.298)\end{array}$ \\
\hline $\operatorname{logit}\left(S_{1}\right)$ & $\begin{array}{c}-0.011(-0.014,-0.007) \\
(1.000)\end{array}$ & $\begin{array}{c}-0.003(-0.012,0.006) \\
(0.752)\end{array}$ & $\begin{array}{c}-0.006(-0.022,0.009) \\
(0.767)\end{array}$ & $\begin{array}{c}0.002(-0.022,0.026) \\
(0.437)\end{array}$ \\
\hline $\operatorname{logit}\left(S_{2}\right)$ & $\begin{array}{c}-0.010(-0.015,-0.005) \\
(1.000)\end{array}$ & $\begin{array}{c}-0.003(-0.014,0.007) \\
(0.742)\end{array}$ & $\begin{array}{c}-0.001(-0.019,0.016) \\
(0.547)\end{array}$ & $\begin{array}{c}0.005(-0.020,0.033) \\
(0.358)\end{array}$ \\
\hline $\operatorname{logit}\left(S_{3}\right)$ & $\begin{array}{c}-0.007(-0.013,-0.002) \\
(0.998)\end{array}$ & $\begin{array}{c}-0.001(-0.010,0.009) \\
(0.596)\end{array}$ & $\begin{array}{c}-0.002(-0.017,0.013) \\
(0.618)\end{array}$ & $\begin{array}{c}0.003(-0.019,0.026) \\
(0.400)\end{array}$ \\
\hline $\operatorname{logit}\left(S_{4}\right)$ & $\begin{array}{c}-0.011(-0.022,-0.002) \\
(0.995)\end{array}$ & $\begin{array}{c}-0.003(-0.019,0.014) \\
(0.692)\end{array}$ & $\begin{array}{c}-0.002(-0.027,0.021) \\
(0.575)\end{array}$ & $\begin{array}{c}0.004(-0.027,0.040) \\
(0.397)\end{array}$ \\
\hline
\end{tabular}

all cases (Table 1, second column). This reflects the pattern seen in Fig. 3B. There is a slight negative effect of age class 2 females on survival, but the pattern relationship is quite weak.

The mean of the posterior $\beta_{N_{3}}$ was always negative but the CRI included zero in all cases (Table 1, third column). This reflects the patterns seen in Figs. 2C and 3C. There is no effect of the number of females in age class 3 on recruitment rates and survival rates of all age classes.

The mean of the posterior $\beta_{N_{4}}$ was always positive and CRI included zero (Table 1, fourth column). This indicates that the number of females in age class 4 had no effect on recruitment rates (Fig. 2D) and survival rates (Fig. 3D) of all age classes.

\section{The age-specific demographic responses to age-class numbers}

The number of females in age class 1 affected recruitment rates of all age classes with different intensities. The probability that the negative effect of the number of females in age class 1 was stronger on recruitment rate of age class 1 than on recruitment for all other age classes $\left(P\left(\beta_{F_{1}, N_{1}}<\beta_{F_{i}, N_{1}}\right)\right.$ for $i=2,3$ or 4$)$ was $>75.6 \%$ (Table 1, Fig. $2 \mathrm{~A}$ ). In contrast, the number of females in age class 1 affected survival of all age classes with similar intensity except age class 3 was less intensively affected. Indeed, the probability that the negative effect of the number of females in age class 1 was lower on survival rate of age class 3 than on survival for all other age classes $\left(P\left(\beta_{S_{i}, N_{1}}<\beta_{S_{3}, N_{1}}\right)\right.$ for $i=1,2$ or 4) was $>75.2 \%$ (Table 1, Fig. $3 \mathrm{~A}$ ). The number of females in age class 2 affected recruitment rates of all age classes with different intensities. The probability that the negative effect of the number of females in age class 2 was stronger on recruitment rate of age class 1 than on recruitment for all other age classes $\left(P\left(\beta_{F_{1}, N_{2}}<\beta_{F_{i, N}}\right)\right.$ for $i=2,3$ or 4 ) was $>62.1 \%$ (Table 1 , Fig. 2B).

\section{The effects of age-class numbers on population growth rate}

The mean of the posterior $\beta_{\lambda, N_{\text {tot }}}$ was estimated to be $-0.009,95 \%$ CRI $(-0.010,-0.008)$ and the probability that $\beta_{\lambda, N_{\text {tot }}}$ was negative equaled to 1 (Fig. 4). Splitting the contribution of $N_{\text {tot }}$ into the age-specific contribution $N_{i}$, we found that the mean of the posterior $\beta_{\lambda, N_{1}}$ was estimated to be $-0.011,95 \%$ CRI $(-0.012,-0.009)$ and the probability that $\beta_{\lambda, N_{1}}$ was negative equaled to 1 , reflecting that the number of females in age class 1 affected the population growth rate (Fig. 4). The mean of the posterior $\beta_{\lambda, N_{2}}$ was estimated to be $-0.008,95 \%$ CRI $(-0.013$, $-0.004)$ and the probability that $\beta_{\lambda, N_{2}}$ was negative equaled to 1 , reflecting that the number of females in age class 2 affected the population growth rate too (Fig. 4). The mean of the posterior $\beta_{\lambda, N_{3}}$ was estimated to be $-0.005,95 \%(-0.013,0.002)$ and the probability that $\beta_{\lambda, N_{3}}$ was negative equaled to $90.9 \%$. The posterior mean of age class 3 's effect on $\lambda$ was much closer to 0 (no effect) than for age class 1 or age class 2 and the posterior distribution was much more diffuse for age class 3 (Fig. 4). Finally, the mean of the posterior $\beta_{\lambda, N_{4}}$ was estimated to be $-0.002,95 \%$ CRI $(-0.016,0.011)$ and the probability 

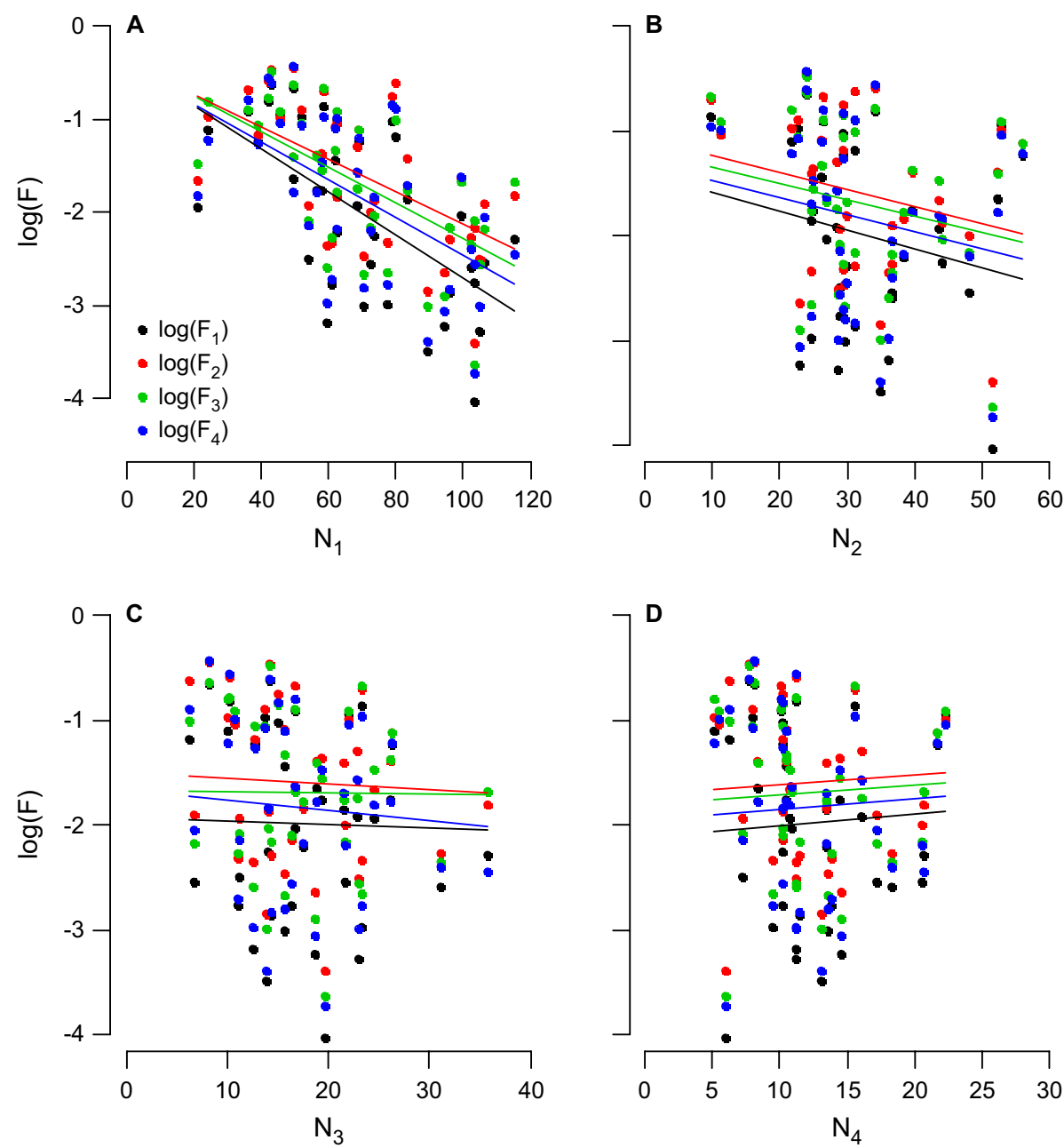

FIg. 2. Posterior means of the annual recruitment rates $F_{i, t}$ (on a log-scale) of each age class $i$ plotted against posterior means of the annual age-specific numbers $N_{j, t}$. Solid lines correspond to the predicted relationship between recruitment rates and numbers from Eq. 1.

that $\beta_{\lambda, N_{4}}$ was negative equaled to $60.2 \%$. The posterior mean of age class 4's effect on $\lambda$ was close to 0 (no effect) and the posterior distribution was extremely diffuse (Fig. 4).

\section{DisCUSSION}

We found that age-specific numbers of females have different effects on demographic rates and also on population growth rate of this great tit population. In particular, the number of females in age class 1 , corresponding to females in their first year of breeding, strongly affected survival and recruitment of all age classes and also the population growth rate. Moreover, we showed that age classes differently respond to an increase in the number of breeding females. These findings question the assumption that all adult individuals can be treated as having an equal contribution to density regulation and that the effect of the number of individuals is age independent. This assumption is commonly made when investigating the strength and effects of density dependence on populations.

Natural populations are regulated by both stochastic and deterministic (i.e., density-dependent) factors (Lack 1954), this great tit population is no exception. Indeed, Grøtan et al. (2009) have recently shown that environmental stochastic effects, such as the amount of seeds of beeches present in the winter and the spring temperature, could influence the dynamics of the population of great tits in the Hoge Veluwe National Park. We showed here that the population is also strongly affected by the number of breeding females present in the population (Fig. 4). These results are in line with previous studies on this population (Both 1998a, Both et al. 1999, 2000, Reed et al. 2013a) that found strong density dependence. We found clear evidence for both density-dependent survival and recruitment into the breeding population. Until now, investigations of density-dependent survival in birds have 

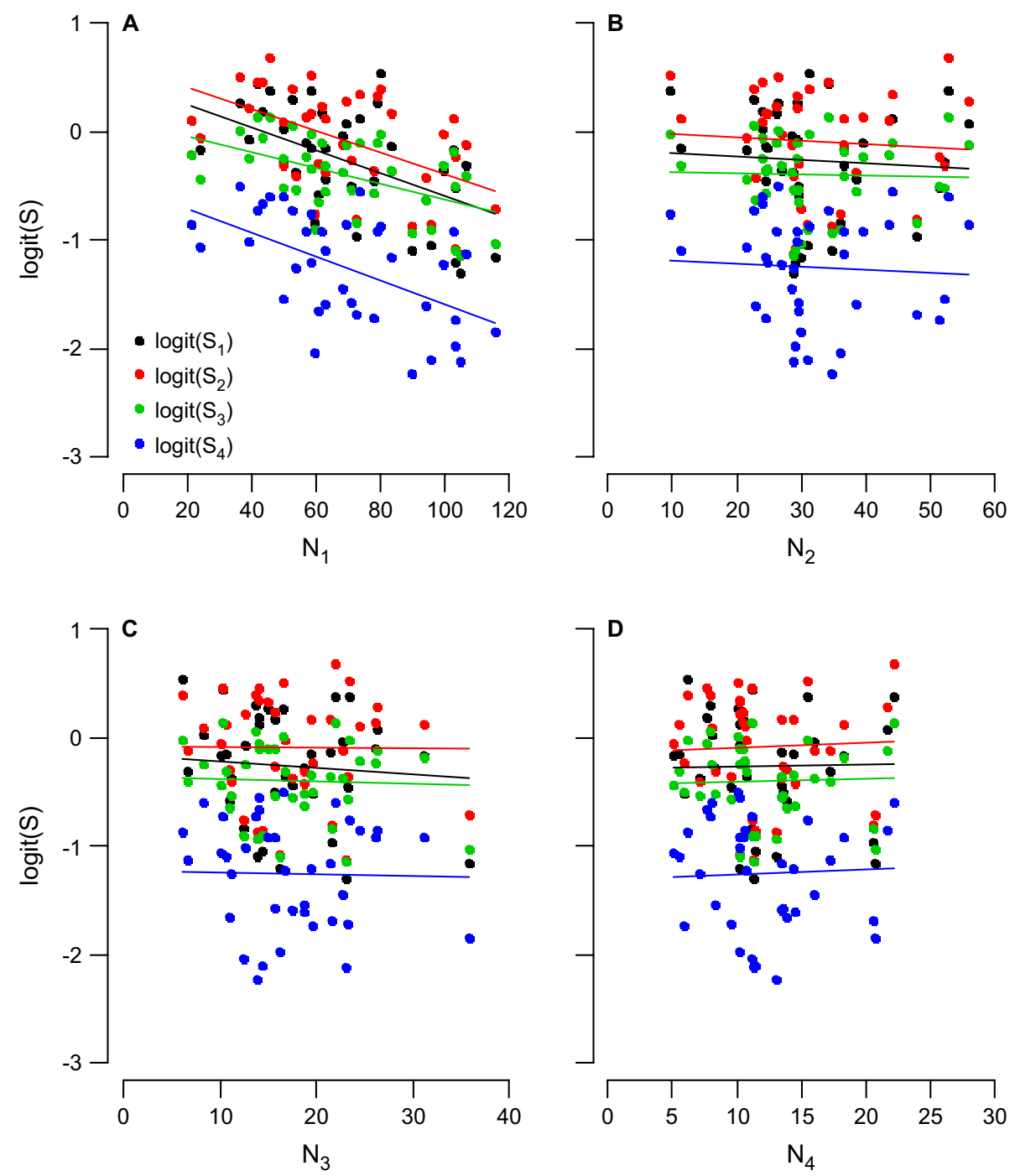

FIg. 3. Posterior means of the annual survival rates $S_{i, t}$ (on a log-scale) of each age class $i$ plotted against posterior means of the annual age-specific numbers $N_{j, t}$ between 1974 and 2012. Solid lines correspond to the predicted relationship between survival rates and numbers from Eq. 2.

remained scarce in the literature (but see e.g., Both et al. 1999, Reed et al. 2013b). In his recent book, Dhondt (2011) pointed out that a large number of studies explored to what extent reproduction decreases with density "while very few studies attempted to determine if [...] survival also decrease[s]."

In addition to its effect on survival, competition has been shown to be the underlying mechanism leading to density-dependent fecundity (see e.g., Both 1998a for an experimental study). More specifically, we have highlighted a decrease of the number of daughters produced that will recruit into the local population, when the number of breeding females increases. Such a decrease of the number of recruits may correspond to effects of the number of females at different life history stages. For instance, competition for food before and during egg laying can alter the amount of energy allocated to reproduction (Lack 1966, Both et al. 2000) leading to density-dependent reduction of clutch size as it has previously been reported in this population (Both 1998b). Moreover, variation in population size can also directly affect nestlings survival by decreasing rates of chick feeding (Sillett and Holmes 2002) or by decreasing the probability that an individual recruits into the local population (Drent 1984). In support of that, it has been shown that survival in the first year of life is strongly density-dependent in that great tit population (Both et al. 1999, Reed et al. 2013b) and recent work has even highlighted that the number of new recruits a given year was unrelated to the number of fledglings produced the previous year because of increased competition for limited resources in their first year of life (Reed et al. 2013a). All these effects of the number of females on the clutch size, and/or later on the number of nestlings and/or later on 


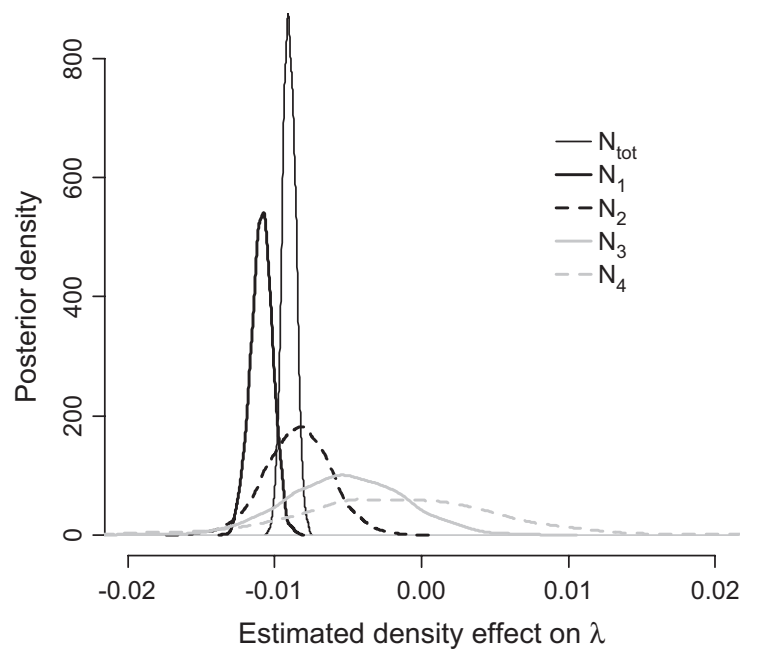

FIG. 4. Posterior distribution of $\beta_{\lambda, N_{j}}$ (the estimated effect of the number of breeding females in age class $j$ on the population growth rate $\lambda$ ). The thick lines are the age-specific posterior distribution $\left(\beta_{\lambda, N}\right)$ and the thin line is the effect of the total number of breeding females on $\lambda\left(\beta_{\lambda, N_{t o t}}\right)$.

the number of females that will effectively remain in the local population to breed, explained the negative effect of the number of females on the number of recruits we found at the end.

If survival and recruitment decrease for all age classes with increasing population size, the intensity of such a decrease is age-specific. In particular, the negative effect of the number of females was stronger on recruitment rate of age class 1 than on recruitment for all other age classes. As the great tit is characterized with high breeding territory fidelity, these findings suggest that when the number of breeding females increases in the population, strong intraspecific competition occurs leading to a reduction of recruitment rates particularly important for the youngest age class. This age-specific demographic response to an increase of the population size has also been found in a variety of taxa. For instance, in Soay sheep (Ovis aries), survival of lambs and old females was affected by density, whereas survival of prime adults and yearlings was not associated with density (Coulson et al. 2001). More generally, it has been shown that in large herbivores, the negative effect of population size is stronger on juvenile survival than on adult survival (Gaillard et al. 1998). In contrast, in the red-backed shrikes, density effects were stronger on adult survival than on juvenile survival (Abadi et al. 2012).

In addition to investigating which age classes were affected by an increase of population size, we explored here the effect of the age-specific numbers on demographic rates and population growth rate. Indeed, we explored the "per capita" effects on density dependence, i.e., the density-dependent effect of an individual of a given age class on another individual. We showed that an increase in the number of females in age class 1, specifically, had a negative effect on survival and recruitment rates of all ages (Table 1). Moreover, an increase in the number of females in age class 2 had a negative effect on recruitment rates of all age classes (Table 1). Such findings may be explained in light of great tit life history. These age classes bring together new breeders attempting to take a territory. In such a shortlived species with high breeding territory fidelity, these age classes have the strongest competitive effect on other breeding females. Looking at the effect of the number of females on the population growth rate $(\lambda)$, we decomposed the effect of total number of breeding females into the effects of age-specific numbers (Fig. 4). Unsurprisingly, the number of females in age class 1 affected $\lambda$ the most, followed by the number of females in age class 2 . Thus, these age classes may be defined as the critical age classes (sensu Charlesworth 1972, 1973) for that population.

It is noteworthy that the critical age classes constitute here the highest proportion of the population. From age class 2 onwards, survival rates start to decrease with ages (Fig. 1B) explaining why only $22.8 \%$ of the breeding population corresponds to females of age class 3 and older. This decline of survival with increasing ages provides additional support for actuarial senescence in this short-lived species, as recently shown in another great tit population (Bouwhuis et al. 2012). Interestingly, and likely due to a decline in brood size and fledgling number produced by the oldest breeding females (Bouwhuis et al. 2009), recruitment rates also decrease from age 2 onwards (Fig. 1B). Therefore, we highlighted that the senescent age classes 3 and 4 were not the critical age classes. These findings also point out the critical role of the youngest age classes in the demography of our population.

\section{Conclusions}

According to Charlesworth (1973):

"In any particular case, this density regulation must occur in response to the number of individuals in a specific group of ages, which I shall call the 'critical age group.' The critical age group might, for example, be composed of all individuals of reproductive age, or of newborn individuals, depending on the biology of the population."

From this pioneering definition of the critical age class, we explored how the different age classes contributed to the observed variation in age-specific demographic rates and population growth rate in a great tit population. We highlighted that the youngest age classes were the critical age classes. We also found age-specific demographic responses to an increase of the number of breeding females in the population. We thus found clear empirical evidence that the assumption of equal responses and equal contribution of all age classes to density dependence may be violated in natura. 


\section{ACKNOWLEDGMENTS}

We are grateful to all those who have collected data and Louis Vernooij for maintaining the long-term great tit database. We warmly thank Elizabeth Holmes and two anonymous referees for their helpful and constructive comments on a previous draft. This work was partly supported by the European Research Council (grant STOCHPOP to BES and ERC-2013AdG 339092 to MEV) and by the Research Council of Norway through its Centres of Excellence funding scheme, project number 223257 .

\section{Literature Cited}

Abadi, F., O. Gimenez, R. Arlettaz, and M. Schaub. 2010. An assessment of integrated population models: bias, accuracy, and violation of the assumption of independence. Ecology 91:7-14.

Abadi, F., O. Gimenez, H. Jakober, W. Stauber, R. Arlettaz, and M. Schaub. 2012. Estimating the strength of density dependence in the presence of observation errors using integrated population models. Ecological Modelling 242:1-9.

Bauchau, V., and A. J. Van Noordwijk. 1995. Comparison of survival estimates obtained from three different methods of recapture in the same population of the great tit. Journal of Applied Statistics 22:1031-1038.

Beddington, J. R. 1974. Age distribution and the stability of simple discrete time population models. Journal of Theoretical Biology 47:65-74.

Berryman, A. A., M. Lima Arce, and B. A. Hawkins. 2002. Population regulation, emergent properties, and a requiem for density dependence. Oikos 99:600-606.

Besbeas, P., S. N. Freeman, B. J. T. Morgan, and E. A. Catchpole. 2002. Integrating mark-recapture-recovery and census data to estimate animal abundance and demographic parameters. Biometrics 58:540-547.

Bonenfant, C., et al. 2009. Chapter 5 empirical evidence of density-dependence in populations of large herbivores. Pages 313-357 in H. Caswell, editor. Advances in Ecological Research. Academic Press, Cambridge, Massachusetts, USA.

Both, C. 1998a. Experimental evidence for density dependence of reproduction in great tits. Journal of Animal Ecology 67:667-674.

Both, C. 1998b. Density dependence of clutch size: Habitat heterogeneity or individual adjustment? Journal of Animal Ecology 67:659-666.

Both, C., M. E. Visser, and N. Verboven. 1999. Densitydependent recruitment rates in great tits: the importance of being heavier. Proceedings of the Royal Society B: Biological Sciences 266:465.

Both, C., J. M. Tinbergen, and M. E. Visser. 2000. Adaptive density dependence of avian clutch size. Ecology 81:3391-3403.

Bouwhuis, S., B. C. Sheldon, S. Verhulst, and A. Charmantier. 2009. Great tits growing old: selective disappearance and the partitioning of senescence to stages within the breeding cycle. Proceedings. Biological Sciences/The Royal Society 276:2769-2777.

Bouwhuis, S., R. Choquet, B. C. Sheldon, and S. Verhulst. 2012. The forms and fitness cost of senescence: age-specific recapture, survival, reproduction, and reproductive value in a wild bird population. American Naturalist 179:E15-E27.

Brook, B. W., and C. J. A. Bradshaw. 2006. Strength of evidence for density dependence in abundance time series of 1198 species. Ecology 87:1445-1451.

Brooks, S. P., and A. Gelman. 1998. General methods for monitoring convergence of iterative simulations. Journal of Computational and Graphical Statistics 7:434-455.
Charlesworth, B. 1972. Selection in populations with overlapping generations. III. Conditions for genetic equilibrium. Theoretical Population Biology 3:377-395.

Charlesworth, B. 1973. Selection in populations with overlapping generations. V. Natural selection and life histories. American Naturalist 107:303-311.

Choquet, R., J.-D. Lebreton, O. Gimenez, A.-M. Reboulet, and R. Pradel. 2009. U-CARE: utilities for performing goodness of fit tests and manipulating CApture-REcapture data. Ecography 32:1071-1074.

Coulson, T., E. A. Catchpole, S. D. Albon, B. J. T. Morgan, J. M. Pemberton, T. H. Clutton-Brock, M. J. Crawley, and B. T. Grenfell. 2001. Age, sex, density, winter weather, and population crashes in Soay Sheep. Science 292:1528-1531.

Coulson, T., et al. 2008. Estimating the functional form for the density dependence from life history data. Ecology 89:1661-1674

de Valpine, P., and A. Hastings. 2002. Fitting population models incorporating process noise and observation error. Ecological Monographs 72:57-76.

Dennis, B., and M. L. Taper. 1994. Density dependence in time series observations of natural populations: estimation and testing. Ecological monographs 64:205-224.

Dennis, B., J. M. Ponciano, S. R. Lele, M. L. Taper, and D. F. Staples. 2006. Estimating density dependence, process noise, and observation error. Ecological Monographs 76:323-341.

Dhondt, A. A. 2011. Interspecific competition in birds. Oxford University Press, Oxford, UK.

Drent, P. J. 1984. Mortality and dispersal in summer and its consequences for the density of great tits Parus major at the onset of autumn. Ardea 72:127-162.

Freckleton, R. P., A. R. Watkinson, R. E. Green, and W. J. Sutherland. 2006. Census error and the detection of density dependence. Journal of Animal Ecology 75:837-851.

Gaillard, J.-M., M. Festa-Bianchet, and N. G. Yoccoz. 1998. Population dynamics of large herbivores: variable recruitment with constant adult survival. Trends in Ecology and Evolution 13:58-63.

Graham, M. H. 2003. Confronting multicollinearity in ecological multiple regression. Ecology 84:2809-2815.

Grøtan, V., B.-E. Sæther, S. Engen, J. H. Van Balen, A. C. Perdeck, and M. E. Visser. 2009. Spatial and temporal variation in the relative contribution of density dependence, climate variation and migration to fluctuations in the size of great tit populations. Journal of Animal Ecology 78:447-459.

Hilborn, R., and C. J. Walters. 2003. Quantitative fisheries stock assessment: choice, dynamics and uncertainty. Springer Science \& Business Media, New York, New York, USA.

Husby, A., L. E. B. Kruuk, and M. E. Visser. 2009. Decline in the frequency and benefits of multiple brooding in great tits as a consequence of a changing environment. Proceedings of the Royal Society B: Biological Sciences 276:1845-1854.

Kéry, M., and M. Schaub. 2012. Bayesian population analysis using WinBUGS: a hierarchical perspective. Academic Press, Boston, Massachusetts, USA.

Krebs, C. J. 2002. Two complementary paradigms for analysing population dynamics. Philosophical Transactions of the Royal Society B: Biological Sciences 357:1211-1219.

Lack, D. L. 1954. The natural regulation of animal numbers. Clarendon Press, Oxford, UK.

Lack, D. 1966. Population studies of birds. Clarendon P, Oxford.

Lande, R., S. Engen, B.-E. Saether, F. Filli, E. Matthysen, and H. Weimerskirch. 2002. Estimating density dependence from population time series using demographic theory and lifehistory data. American Naturalist 159:321-337. 
Lande, R., S. Engen, and B.-E. Saether. 2003. Stochastic population dynamics in ecology and conservation. Oxford University Press, Oxford New York, New York, USA.

Lebreton, J.-D., and O. Gimenez. 2013. Detecting and estimating density dependence in wildlife populations. The Journal of Wildlife Management 77:12-23.

Lebreton, J.-D., K. P. Burnham, J. Clobert, and D. R. Anderson. 1992. Modeling survival and testing biological hypotheses using marked animals: a unified approach with case studies. Ecological Monographs 62:67-118.

Lillegård, M., S. Engen, B.-E. Sæther, V. GrØtan, and M. C. Drever. 2008. Estimation of population parameters from aerial counts of North American mallards: a cautionary tale. Ecological Applications 18:197-207.

Perrins, C. 1979. British tits. First edition. Collins, London, UK.

Perrins, C. M., and R. H. McCleery. 1989. Laying dates and clutch size in the great tit. The Wilson Bulletin 101: 236-253.

Plummer, M. 2003. JAGS: a program for analysis of Bayesian graphical models using Gibbs sampling. Pages 20-22 in K. Hornik, F. Leisch, and A. Zeileis, editors. Proceedings of the 3 rd international workshop on distributed statistical computing. Technische Universität Wien, Vienna, Austria.

Price, B., C. A. McAlpine, A. S. Kutt, S. R. Phinn, D. V. Pullar, and J. A. Ludwig. 2009. Continuum or discrete patch landscape models for savanna birds? Towards a pluralistic approach. Ecography 32:745-756.

Price, B., A. S. Kutt, and C. A. McAlpine. 2010. The importance of fine-scale savanna heterogeneity for reptiles and small mammals. Biological Conservation 143:2504-2513.

R Development Core Team. 2011. R: a language and environment for statistical computing. R Foundation for Statistical Computing, Vienna, Austria. https://www.r-project.org/

Reed, T. E., V. Grøtan, S. Jenouvrier, B.-E. Sæther, and M. E. Visser. 2013a. Population growth in a wild bird is buffered against phenological mismatch. Science 340:488-491.
Reed, T. E., S. Jenouvrier, and M. E. Visser. 2013b. Phenological mismatch strongly affects individual fitness but not population demography in a woodland passerine. The Journal of Animal Ecology 82:131-144.

Ricker, W. E. 1954. Stock and recruitment. Journal of the Fisheries Research Board of Canada 11:559-623.

Royama, T. 1992. Analytical population dynamics. Springer Science \& Business Media, New York, New York, USA.

Sæther, B.-E., S. Engen, and R. Lande. 1996. Densitydependence and optimal harvesting of fluctuating populations. Oikos 76:40-46.

Sæther, B.-E., S. Engen, and E. Matthysen. 2002. Demographic characteristics and population dynamical patterns of solitary birds. Science 295:2070-2073.

Schaub, M., and F. Abadi. 2011. Integrated population models: a novel analysis framework for deeper insights into population dynamics. Journal of Ornithology 152:227-237.

Schaub, M., T. S. Reichlin, F. Abadi, M. Kéry, L. Jenni, and R. Arlettaz. 2012. The demographic drivers of local population dynamics in two rare migratory birds. Oecologia 168:97-108.

Schaub, M., H. Jakober, and W. Stauber. 2013. Strong contribution of immigration to local population regulation: evidence from a migratory passerine. Ecology 94:1828-1838.

Sillett, T. S., and R. T. Holmes. 2002. Variation in survivorship of a migratory songbird throughout its annual cycle. Journal of Animal Ecology 71:296-308.

Sinclair, A. R. E. 1989. Population regulation of animals. Pages 197-241 in J. M. Cherrett, editor. Ecological concepts. Blackwell Scientific, Oxford, UK.

Su, Y. S., and M. Yajima. 2012. R2jags: a package for running jags from R. R package version 0.03-08.

Turchin, P. 1995. Population regulation: old arguments and a new synthesis. Pages 19-40 in N. Cappucino and P. W. Price, editors. Population dynamics. Academic Press, New York New York, USA.

\section{SUPPORTING INFORMATION}

Additional supporting information may be found in the online version of this article at: http://onlinelibrary.wiley.com/doi/10.1002/ ecy.1442/suppinfo 